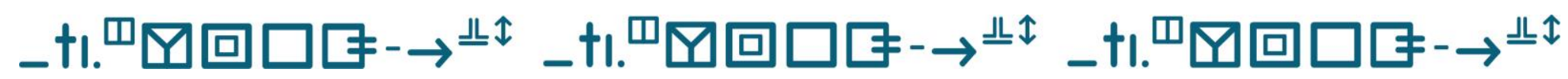

\section{“Luta por reconhecimento": análise crítica dos discursos do Povo Surdo sobre a temática do ENEM 2017}

\section{"Fight for recognition": critical analysis of the deaf people's speech on ENEM 2017}

\footnotetext{
$\infty$

Cleide Emília Faye Pedrosa

Universidade Federal de Sergipe (UFS), Aracaju, Sergipe, Brasil. Universidade de Lisboa, Lisboa, Portugal. cleideemiliafayepedrosa@gmail.com

(iD) 9

Juliana Barbosa Alves

Universidade Federal de Sergipe (UFS), Aracaju, Sergipe, Brasil. julialves01@hotmail.com
}

Resumo: Nesta pesquisa, o objetivo foi, com base na visão crítica das práticas sociais, analisar, por meio das lexias positivas e negativas, os discursos de vitimização e/ou empoderamento da comunidade surda contidos em comentários, no Facebook, sobre o tema da redação do ENEM 2017, a saber "Desafios para a educação de surdos no Brasil". Para isso, buscamos aporte teórico na Análise Crítica do Discurso, nos Estudos Surdos e na Gramática SistêmicoFuncional. Utilizamos a metodologia qualitativointerpretativa, seguindo os passos indicados por Pedrosa (2018) na Abordagem Sociológica e Comunicacional do Discurso. Como resultado, as análises dos discursos nos proporcionaram reflexões sociais sobre as reivindicações do Povo Surdo e sua "Luta por Reconhecimento" de sua cidadania.

Palavras-chave: análise crítica do discurso; luta por reconhecimento; comunidade surda; ENEM 2017. 
Abstract: In this research, the goal, based on the critical view of social practices, was to analyze, through positive and negative lexies, the discourses of victimization and/or empowerment by the deaf community contained in comments, on Facebook, about the ENEM 2017 essay. In order to do so, we sought theoretical support on Critical Discourse Analysis, Deaf Studies, and on Systemic-Functional Grammar. We used a qualitative-interpretative methodology, following the steps indicated by Pedrosa (2018) on the Sociological and Communicative Discourse Approach. As a result, the analyses of discourses offered social reflections on the claims of the Deaf People and their "Fight for Recognition" of their citizenship.

Keywords: critical discourse analysis; fight for recognition; deaf community; ENEM 2017.

Submetido em 09 de setembro de 2021.

Aceito em 11 de novembro de 2021.

Publicado em 17 de fevereiro de 2022. 


\section{_t..}

“Luta por reconhecimento": análise crítica dos discursos do Povo Surdo sobre a temática do ENEM 2017

Cleide Emília Faye Pedrosa • Juliana Barbosa Alves

\section{Introdução}

A educação dos surdos é uma temática que, na atualidade, tem seguido outro caminho diferente da carga histórica vivenciada por esses sujeitos. Na antiguidade, entre vários povos, os surdos eram vistos como inferiores e condenados à morte. Além dessas atrocidades, um fato que muito marcou a história educacional dos surdos foi o Congresso de Milão, em 1880. Nele se instituiu a proibição do uso das línguas de sinais, estabelecendo o oralismo como filosofia educacional (KINSEY, 1880; ROCHELLE, 1880; GESSER, 2009; SOUZA, 2014). Tal fato se configurou como uma perda enorme em avanços nos estudos das línguas de sinais, a língua natural dos surdos, e sobretudo na educação deles.

Leis e Decretos, nacionais e internacionais, têm diminuído essa defasagem no que tange à educação dos surdos. Citamos aqui alguns instrumentos legais relevantes na educação dos surdos brasileiros: a Lei 10.436/2002, que reconhece a Língua Brasileira de Sinais (Libras) como meio legal de comunicação e expressão de pessoas surdas (BRASIL, 2002); o Decreto 5.626/2005, que, dentre outros provimentos, implementa a disciplina Libras como obrigatória nos cursos de licenciatura, pedagogia e fonoaudiologia (BRASIL, 2005); e a Lei 12.319/2010, que reconhece a profissão de tradutor e intérprete de Libras (BRASIL, 2010). Em 2019, determinado pelo Decreto 9.465/2019, foi integrada à Secretaria de Modalidades Especializadas de Educação (SEMESP) a Diretoria de Educação Especial de Políticas de Educação Bilíngue de Surdos do Ministério da Educação (MEC), que pretende formar professores e tradutores e intérpretes de Libras em parceria com o Instituto Nacional de Educação de Surdos (INES) e os Institutos Federais (BRASIL, 2019). Ainda no ano de 2019, ocorreram significativos avanços na promoção de visibilidade para a 


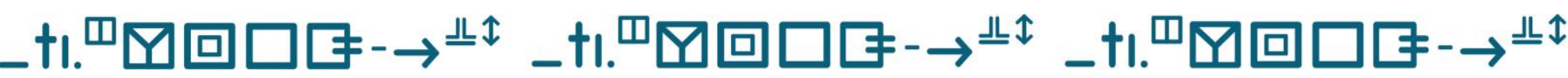

“Luta por reconhecimento": análise crítica dos discursos do Povo Surdo sobre a temática do ENEM 2017

Cleide Emília Faye Pedrosa • Juliana Barbosa Alves

comunidade surda. No atual governo federal, independentemente de outras questões críticas, foram nomeadas duas surdas para cargos no MEC. Priscilla Gaspar assumiu o cargo de Secretária ${ }^{2}$ Nacional sobre Direitos das Pessoas com Deficiência do Ministério da Mulher, da Família e dos Direitos Humanos. Em setembro de 2021 foi exonerada e assumiu o cargo de Diretora do Departamento de Políticas Temáticas dos Direitos da Pessoa com Deficiência da Secretaria Nacional dos Direitos da Pessoa com Deficiência do Ministério da Mulher, da Família e dos Direitos Humanos ${ }^{3}$. A segunda nomeada foi a professora Karin Strobel, assumindo o cargo de Diretora ${ }^{4}$ de Políticas de Educação Bilíngue de Surdos da Secretaria de Modalidades Especializadas de Educação, no âmbito do Ministério da Educação. A professora foi exonerada do cargo em janeiro de $2020^{5}$.

Por estarmos trabalhando com esse grupo vulnerável, minoritário linguisticamente, na busca por lhe dar visibilidade, iremos dialogar com a Análise Crítica do Discurso (ACD), que tem seu objetivo centrado em desvelar práticas sociais hegemônicas (FAIRCLOUGH, 2008; RESENDE, 2017; PEDROSA, 2018) e denunciar as relações de poder e de opressão sofridas por grupos vulneráveis (GONÇALVES-SEGUNDO, 2018). Farão parte ainda do aporte teórico, a teoria da Luta por Reconhecimento (HONNETH, 2009) e os Estudos Surdos (QUADROS, 1997; GESSER, 2009; SOUZA, 2014).

Sabendo que as análises em ACD atendem não somente ao caráter social e discursivo, mas também ao caráter linguístico, por serem textualmente orientadas, utilizaremos a Gramática Sistêmico-Funcional, mais precisamente seu Sistema de Avaliatividade (ALMEIDA, 2010; SOUZA, 2010). Para isto, é mister ressaltar o caráter desta gramática que é baseada na língua em uso. A avaliatividade aqui, por sua vez, é evocada por apresentar de que forma os textos/discursos, através de sua estrutural 


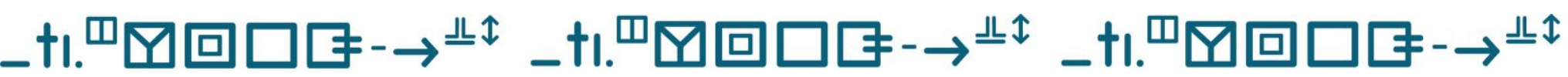

“Luta por reconhecimento": análise crítica dos discursos do Povo Surdo sobre a temática do ENEM 2017

Cleide Emília Faye Pedrosa • Juliana Barbosa Alves

lexical e gramatical, desvelam-nos práticas avaliativas negativas e/ou positivas dos usuários da língua.

Partindo dos aportes teóricos expostos, nosso objetivo é analisar, por meio das lexias positivas e negativas, os discursos de vitimização e/ou empoderamento da comunidade surda contidos em comentários, no Facebook, sobre o tema da redação do ENEM 2017, a saber "Desafios para a educação de surdos no Brasil".

A fim de apresentar a proposta da pesquisa, este artigo apresenta a seguinte configuração: exposição sobre o histórico da ACD e seu engajamento com as minorias; Estudos Surdos (ES); Teoria da Luta por Reconhecimento e seu imbricamento com a ACD e os ES; metodologia; análises críticas dos discursos dos Surdos sobre a temática do ENEM 2017; e conclusões advindas dos achados analisados.

\section{Análise Crítica do Discurso e seu engajamento com as lutas e o empoderamento das minorias}

A ACD, o principal aporte teórico desse trabalho, procura, em seus objetivos, a denúncia e divulgação de problemas sociais. Nós, analistas críticos do discurso, nos engajamos com a conscientização e o empoderamento dos que são vítimas das relações de abuso de poder (PEDROSA, 2008; MELO, 2018).

Desde sua consolidação, na década de 1990, a ACD tem se mostrado um campo em constante crescimento, apresentando uma base teórica e metodológica para as análises sociais, consolidadas discursivamente. Desta forma, apresentaremos abaixo, para uma melhor contextualização, um registro histórico da $A C D$, a prática da $A C D$ do linguístico ao social e as convergências políticas da ACD. 


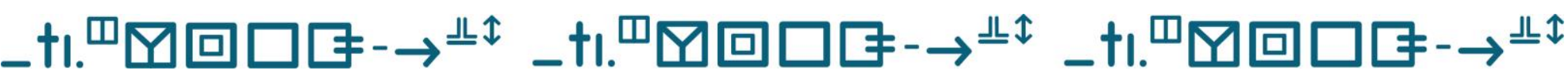

“Luta por reconhecimento": análise crítica dos discursos do Povo Surdo sobre a temática do ENEM 2017

Cleide Emília Faye Pedrosa • Juliana Barbosa Alves

\subsection{Um registro para não perder o histórico}

A Análise Crítica do Discurso teve seu despertar como uma nova teoria linguística, discursiva e social no final da década de 1980 e início da década de 1990, com a publicação de Teun van Dijk, Discourse and Society (VAN DIJK, 1997). Contudo, em anos anteriores, outras obras já despontavam com o novo pensamento da linguagem: Norman Fairclough com Language and power em 1989; Ruth Wodak com Language, power and ideology em1989, Teun van Dijk com Prejudice in Discourse em 1984, conforme informações em Melo (2018).

Teun van Dijk (1997) propagou os estudos críticos do discurso na América Latina, principalmente na Argentina, no Brasil e no México. Para o autor, os estudos do discurso tiveram ascensão na América Latina maior que em qualquer outro continente, fazendo parte como disciplina em Linguística, Estudos Literários e Estudos de Comunicação.

No Brasil, os estudos da Análise Crítica do Discurso deram um grande passo com a tradução do livro de Fairclough, Discourse and social change (1992), por Izabel Magalhães, em 2001, publicado pela editora UnB (FAIRCLOUGH, 2008). Dessa forma, a pesquisadora proporcionou o acesso a uma obra marco da ACD. Destacamos ainda algumas obras que se lançaram nesse cenário inicial: na UFMG, pontuamos o livro Reflexões sobre a Análise Crítica do Discurso (2001), de Célia Magalhães como organizadora (MAGALHÃES, 2001); na UFS, citamos o livro de Cleide Pedrosa, em 2008, Análise Crítica do Discurso: do linguístico ao social no gênero midiático, com base em sua tese defendida em 2005 (PEDROSA, 2008) e ainda, na UFSC, também em 2008, o livro Desvendando discursos: conceitos básicos, tendo como organizadores Caldas-Coulthard e Scliar-Cabral (CALDAS- 


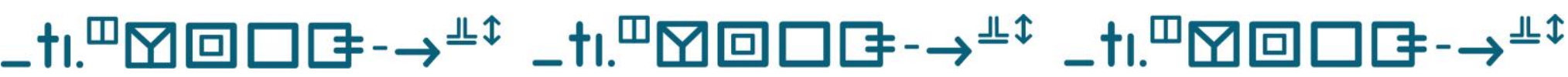

“Luta por reconhecimento": análise crítica dos discursos do Povo Surdo sobre a temática do ENEM 2017

Cleide Emília Faye Pedrosa • Juliana Barbosa Alves

COULTHARD; SCLIAR-CABRAL, 2008). Além disso, há outras contribuições, como a grande produção de Viviane de Melo Resende, como exemplos: Análise de Discurso Crítica (2006) (RESENDE; RAMALHO, 2006) e Análise de discurso (para a) crítica: o texto como material de pesquisa (2011) (RESENDE; RAMALHO, 2011).

Citamos aqui, também, publicações recentes no Brasil em contribuição à $A C D$, como o livro de Viviane Resende e Jacqueline Fiuza Regis, Outras perspectivas em análise de discurso crítica (2017) (RESENDE; REGIS, 2017); o livro de Izabel Magalhães, André Martins e Viviane Resende, Análise de discurso crítica: um método de pesquisa qualitativa (2017) (MAGALHÃES, MARTINS, RESENDE, 2017), o livro organizado por José Ribamar Batista Jr., Denise Sato e Iran Melo, Análise de discurso crítica para linguistas e não linguistas (2018) (BATISTA; SATO; MELO, 2018); ainda da Viviane Resende (Org.), o livro Decolonizar os estudos críticos do discurso (2019) (RESENDE, 2019); a obra de Lucineudo Machado Irineu et al. (Orgs.), Análise de Discurso Crítica: conceitos-chave (2020) (IRINEU et al., 2020). Com isso, podemos aferir que, no Brasil, temos um bom aporte teórico sobre a ACD.

\subsection{Estudos em Análise Crítica do Discurso: prática de linguagem e prática social}

A ACD tem seu objetivo centrado em ancorar a denúncia de problemas sociais particulares quando levanta a bandeira de que a linguagem tem uma relação especial com outros elementos sociais. Para esse tipo de análise do discurso, os textos que formulamos, funcionam como parte essencial das maneiras como nos comportamos na sociedade, portanto, podemos dizer que eles são efeitos das situações sociais e 


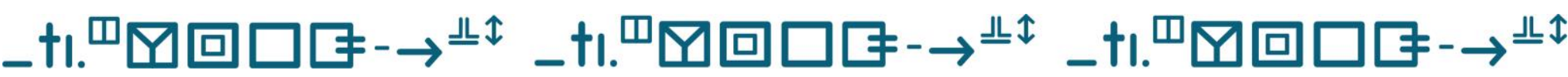

“Luta por reconhecimento": análise crítica dos discursos do Povo Surdo sobre a temática do ENEM 2017

Cleide Emília Faye Pedrosa • Juliana Barbosa Alves

também influenciam estas mesmas situações sociais (RESENDE, 2017). Não obstante, as ciências críticas também devem fomentar a reflexão para que o sujeito consiga enxergar as entrelinhas das situações que, por vezes, são naturalizadas, principalmente aquelas em que ele se encontra em situação de opressão. Esse passo é decisivo para que ele possa construir sua própria trajetória de Luta por Reconhecimento e, com isso, conquistar seu empoderamento (HONNETH, 2009; MELO, 2018).

Por essa razão, a ACD não se identifica apenas como uma proposta exclusivamente científica da linguagem, mas também como uma abordagem que procura compreender, combater e desvendar as desigualdades sociais de todos os tipos, suplantando o cerne das entidades de pesquisa. Com isso, a ACD assume uma posição de engajamento para construir ações que visem o empoderamento e a conscientização daqueles que se encontram em situações de opressão (MELO, 2018).

Quando se trabalha com uma abordagem crítica do discurso, podemos pensar também em uma abordagem da vida social, sendo preciso considerar as coerções estruturais das variadas práticas sociais nas quais estamos inseridos. Devemos considerar, simultaneamente, nossa capacidade de agir e, sobretudo, de refletir e de resistir, para que possamos perceber o objetivo principal dessa prática, que é a denúncia de relações de poder e de opressão, a fim de possibilitar uma sociedade equitativa em que todos tenham direitos iguais. A busca por uma sociedade justa é inevitável para a ciência crítica. Entretanto, para que essas noções sejam fixadas, é necessário refletir de quais contextos sócio-históricos elas surgem, bem como quais as articulações que as permeiam e de que maneira elas se sustentam ou se modificam. É necessário verificar como essas práticas se manifestam em discursos e como estes, que por sua vez, controlam a vida 


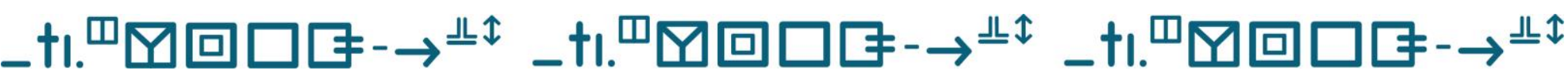

“Luta por reconhecimento": análise crítica dos discursos do Povo Surdo sobre a temática do ENEM 2017

Cleide Emília Faye Pedrosa • Juliana Barbosa Alves

em sociedade, a fim de analisá-lo criticamente (GONÇALVES-SEGUNDO, 2018).

\subsection{Os vários caminhos da Análise Crítica do Discurso e sua convergência política}

Ao estudar a ACD, identificamos várias propostas de análise advindas de autores e grupos de estudo diferentes, porém o que os une é seu posicionamento político quanto às análises que realizam. Como pontuou Wodak (2003, p. 22), a consolidação desse grupo foi mais resultado de um agendamento e programa de investigação "que pela existência de alguma teoria ou metodologia em comum" ${ }^{\prime 6}$.

Referendadas em Wodak (2003); Fairclough (2003); Wodak e Meyer (2009); Resende (2009) e Melo (2018), resumiremos as correntes tradicionais da ACD. Fairclough propõe uma articulação entre a Linguística Sistêmico-Funcional (LSF) e a Sociologia, criando a abordagem dialéticorelacional. Van Dijk estabelece um diálogo entre Linguística Textual e Psicologia Social, surgindo a abordagem sociocognitiva, que se situa no discurso como canal para a reprodução ideológica, assim seu tripé é o discurso, a cognição e a sociedade. Por seu turno, Wodak direciona suas pesquisas para a Sociolinguística e a História, criando a abordagem histórico-discursiva, cujo objetivo principal é "pesquisar discursos institucionais racistas, antissemitas, entre outros, numa perspectiva sociolinguística e histórico-discursiva, cujo enfoque está no estudo da argumentação e na retórica" (MELO, 2018, p. 30).

As correntes mais atuais da ACD se pronunciam com alguns trabalhos na América Latina. Pardo (2017), na Argentina, criou a teoria e o método sincrônico-diacrônico, em que reúne categorias gramaticalizadas e 


\section{_t..}

“Luta por reconhecimento": análise crítica dos discursos do Povo Surdo sobre a temática do ENEM 2017

Cleide Emília Faye Pedrosa • Juliana Barbosa Alves

categorias semântico-discursivas e trabalha com os textos de maneira indutiva-qualitativa. "Os termos 'sincrônico' e 'diacrônico' [...] referem-se à leitura das categorias. No caso da sincronia, a leitura é linear em cada emissão. A diacronia permite uma leitura longitudinal de cada categoria em sua realização textual" (PARDO, 2017, p. 187, destaque da autora). No Brasil, Magalhães, Martins e Resende (2017, p. 98) expõem sua proposta de abordagem etnográfico-discursiva, a qual "associa métodos etnográficos ao discurso como dimensão da prática social", e busca "uma interpretação do problema específico da prática social que está em discussão numa pesquisa particular" (MAGALHÃES, MARTINS e RESENDE, 2017, p. 117).

Ainda no Brasil, a ASCD, Abordagem Sociológica e Comunicacional do Discurso ${ }^{7}$, surgiu em 2011 e foi fruto das pesquisas da Profa. Dra. Cleide Emília Faye Pedrosa (PEDROSA, 2012) e seu grupo de pesquisa da Universidade Federal do Rio Grande do Norte (UFRN). Essa abordagem tem uma orientação transdisciplinar. Está ancorada em áreas como a Linguística Sistêmico-Funcional, a Linguística Textual, a Sociologia para a Mudança Social, a Sociologia Aplicada à Mudança Social, a Comunicação para a Mudança Social e os Estudos Culturais, que se mostram fundamentais para os analistas críticos do discurso que desejam trabalhar com as mudanças sociais, os tipos de poder, a construção de identidades e os estudos dos sujeitos discursivos. Recentemente, está acrescentando a teoria da Luta por Reconhecimento (HONNETH, 2009), como a aplicação que se fará neste artigo.

Considerando que a proposta da ACD é ser transdisciplinar, dialogaremos, para este artigo, com os Estudos Surdos e a Teoria da "Luta por Reconhecimento". Essa relação dialógica com outras teorias sociais vai muito além de uma relação interdisciplinar, na medida em que avança e 


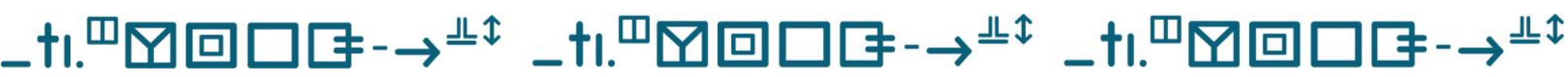

“Luta por reconhecimento": análise crítica dos discursos do Povo Surdo sobre a temática do ENEM 2017

Cleide Emília Faye Pedrosa • Juliana Barbosa Alves

ultrapassa as fronteiras das disciplinas, porque não aplica simplesmente as outras teorias a seu objeto de estudo, mas as operacionaliza e as transforma, a fim de atingir uma abordagem sociodiscursiva (transdisciplinaridade) (RESENDE; RAMALHO, 2006; MELO, 2018).

\section{Estudos Surdos: altercações históricas e filosóficas}

A história da educação dos surdos, mundialmente, passou por fortes períodos sombrios, até chegar, nos dias de hoje, aos vislumbres que presenciamos.

Embora alguns precursores da educação dos surdos, como L'Epée, Gallaudet e Sicard tenham difundido o método de sinalização, a educação dos surdos passou por um período triste, em que alguns nomes influenciaram para que o método da oralização fosse imposto, como Watson, Ponce de Leon, Bonet, Itard e Graham Bell (SOUZA, 2014). Em sua obra de 1868, E. M. Gallaudet aponta o fracasso do método articulatório e esclarece que, "nas escolas europeias, onde a articulação tem sido aceita como um complemento, a confiança principal está sendo na língua de sinais, no alfabeto manual e na escrita" $(1868, \text { p. } 08)^{8}$.

Na Idade Moderna, houve a distinção entre surdez e mudez (CARVALHO, 2007), surgindo, com isso, três abordagens filosóficas na educação dos surdos que foram utilizadas por educadores para ensinar, inicialmente, aos filhos dos nobres. As abordagens filosóficas são: Treinamento da fala ou oralismo: o surdo aprenderia a língua oral para se aproximar o máximo possível do modelo ouvinte; Método combinado ou bimodal: o surdo aprenderia a língua oral e a língua de sinais, a leitura labial e o alfabeto digital, entre outros recursos; Linguagem gestual: o surdo aprenderia a língua 


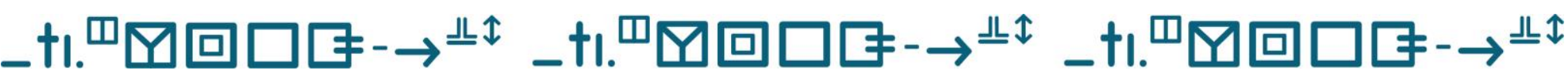

“Luta por reconhecimento": análise crítica dos discursos do Povo Surdo sobre a temática do ENEM 2017

Cleide Emília Faye Pedrosa • Juliana Barbosa Alves

de sinais considerada um importante veículo de aquisição de conhecimento, comunicação e organização do pensamento (QUADROS, 1997; GESSER, 2009).

A fim de contextualizar as críticas sobre estes posicionamentos filosóficos, trazemos Quadros (1997), cuja reflexão sobre as filosofias do oralismo e do bimodalismo aponta que o oralismo desconsidera a Cultura Surda; já no bimodalismo, "a língua de sinais é usada como recurso para o ensino da língua oral", e a estrutura que permanece é a da língua oral, surgindo o português sinalizado (QUADROS, 1997, p. 24). Dentro da proposta do gestualismo, a autora se posiciona como esta sendo um importante caminho de aquisição de conhecimento, comunicação e organização do pensamento por considerar a língua de sinais. Atualmente, estudos apontam a proposta do bilinguismo como um caminho mais adequado para o ensino de surdos, "tendo em vista que considera a língua de sinais como língua natural e parte desse pressuposto para o ensino da língua escrita" (QUADROS, 1997, p. 27).

O uso do oralismo foi reforçado pelas decisões de um evento científico que ocorreu em 1880, o Congresso de Milão. Neste Congresso, o oralismo foi instituído como filosofia oficial de educação dos surdos, sendo o ensino da língua sinalizada proibida nas escolas. O resultado de tal prática comprometeu o desenvolvimento dos surdos em todo o mundo (GESSER, 2009; SOUZA, 2014).

Rochelle, secretária do Congresso para a língua francesa, reporta essa decisão: 


\section{_t..}

“Luta por reconhecimento": análise crítica dos discursos do Povo Surdo sobre a temática do ENEM 2017

Cleide Emília Faye Pedrosa • Juliana Barbosa Alves

[...] mas, apesar de alguma resistência, o método de articulação prevalece visivelmente. Seu triunfo é afirmado em uma resolução assim formulada: O Congresso, Considerando a incontestável superioridade da palavra sobre os sinais para devolver os surdos-mudos à sociedade e dar-lhes um conhecimento mais perfeito da língua, Declara que o método oral deve ser preferido ao mimetismo para a educação e instrução dos surdos-mudos. (ROCHELLE, 1880, p. 10, tradução nossa) $)^{9}$.

Fica, com isso, definida uma injunção que, infelizmente, impera, em várias situações, até os dias atuais. Quadros (1997) repudia essa imposição social da maioria linguística (ouvintes) sobre a minoria linguística de uma língua gesto-visual. Essa, sem dúvida, é uma questão que extrapola um problema educacional, pois se encontra em escala social mais ampla, similar ao enfrentado pelas comunidades indígenas no Brasil e no mundo. Como bem nos alerta o antropólogo Ortúzar (2016), toda sociedade produz suas próprias vítimas de exclusão, resultantes das relações de poder que se estabelecem nela. E, se não buscar a justiça social, estará propensa ao fracasso. Assim, enfrentar essas questões deve ser uma resposta de prática de cidadania, especialmente para quem se engaja politicamente com as causas das minorias, como os analistas críticos do discurso (FAIRCLOUGH, 2008; MAGALHÃES, MARTINS, RESENDE, 2017, PEDROSA, 2018).

Como resposta por justiça social, foi originada, na década de 1970, a filosofia bilíngue, que é a utilização, pelos surdos, da língua de sinais como primeira língua e da língua do seu país como a segunda. Esse tipo de educação vive o auge das reivindicações dos surdos em vários países. Além de artigos, livros e outros materiais defendendo essa educação para as crianças surdas, ressaltamos aqui uma Carta reivindicatória (2012), escrita pelos 7 (sete) primeiros surdos doutores nas áreas de Educação e Linguística do Brasil, dirigida ao Ministro da Educação, Aloizio Mercadante. 


\section{_t..}

“Luta por reconhecimento": análise crítica dos discursos do Povo Surdo sobre a temática do ENEM 2017

Cleide Emília Faye Pedrosa • Juliana Barbosa Alves

Nela, os autores Dra. Ana Regina e Souza Campello, professora adjunta da Universidade Federal do Rio de Janeiro (UFRJ); Dra. Gladis Teresinha Taschetto Perlin, Dra. Karin Lilian Strobel, Dra. Marianne Rossi Stumpf, Dra. Patrícia Luiza Ferreira Rezende, Dr. Rodrigo Rosso Marques, professores adjuntos da Universidade Federal de Santa Catarina (UFSC); Dr. Wilson de Oliveira Miranda, professor adjunto da Universidade Federal de Santa Maria (UFSM), amparados em dados de pesquisas e em Convenções (por exemplo: Convenção Internacional sobre os Direitos das Pessoas com Deficiência), rogam ao Ministro que "GARANTA AS ESCOLAS BILÍNGUES, COM INSTRUÇÃO EM LIBRAS E EM PORTUGUÊS ESCRITO, NAS DIRETRIZES EDUCACIONAIS DO MEC" (CARTA, 2012, p. 07, destaque dos autores).

Não podemos deixar de acrescentar o que presenciamos nos dias de hoje, em que calham também os estudos realizados pelo linguista William Stokoe que levaram a língua de sinais a receber status linguístico, definindo os parâmetros que constituem os sinais (configuração de mão - CM; movimento - M; locação - L), como também a fundação de uma Universidade para surdos, a Universidade Gallaudet, nos EUA, fundada, em 1864, pelo filho de Thomas Gallaudet, indicado como um dos defensores das línguas de sinais e fundador da primeira escola para surdos dos EUA.

No Brasil, a língua de sinais, como a conhecemos hoje, teve início com a fundação do Instituto dos Surdos-Mudos, em 1857, atualmente Instituto Nacional de Educação de Surdos. Vindo da França, o professor Ernest Huet, a convite de Dom Pedro II, trouxe o método combinado. Em 1862, o professor Huet deixou o Instituto e assumiu em seu lugar o Dr. Manuel de Magalhães Couto, que, não tendo conhecimento da educação de surdos, não prosseguiu com o trabalho educacional iniciado por Huet. Com isso, o Instituto tornou-se um asilo de surdos (GESSER, 2012; SOUZA, 2014). 


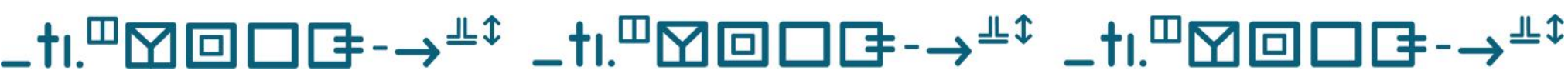

“Luta por reconhecimento": análise crítica dos discursos do Povo Surdo sobre a temática do ENEM 2017

Cleide Emília Faye Pedrosa • Juliana Barbosa Alves

Em 1868, o Instituto voltou a funcionar quando o Dr. Tobias Leite assumiu a direção. Tobias Leite, médico sergipano, dirigiu o Instituto no período de 1868 até 1896 e adotou, durante sua gestão, o método sinalizado, inicialmente, e depois passou a fazer uso do método oralizado na educação dos surdos (SOUZA, 2014). Na gestão da professora Ana Rímoli, em 1896, foi implantado o primeiro curso normal de formação de professores para surdos. E foi na década de 1970 que a professora Ivete Vasconcelos trouxe para o Brasil, dos Estados Unidos, a filosofia da comunicação total.

Devido a essas altercações quanto ao método e ao uso ou não de línguas de sinais, apenas em 2002 a Libras (Língua Brasileira de Sinais) passou a ser legalmente reconhecida como língua própria da comunidade surda do Brasil, servindo como meio legal de comunicação e expressão.

Valendo-se do aporte teórico da ACD, que "objetiva explicitar o que está encoberto no discurso; aquilo que está naturalizado e, por isso, não é imediatamente notado" (VIEIRA; MACEDO, 2018, p. 65-66), percebemos a importância das conquistas da comunidade ao longo dos anos, como o reconhecimento da língua de sinais, para a construção de suas identidades.

Atribui-se importância ao uso da língua de sinais na construção da(s) identidade(s) do surdo, pelo valor que a língua tem como instrumento de comunicação, de troca, de reflexão, de crítica, de posicionamento, pois, como se poderia imaginar uma significativa e natural interação entre surdos que utilizassem uma língua oral ou uma língua oral sinalizada? [...] Não há como negar que o uso da língua de sinais é um dos principais elementos aglutinantes das comunidades surdas, sendo, assim, um dos elementos importantíssimos nos processos de desenvolvimentos da identidade surda/ de surdo e nos de identificação dos surdos entre si (SÁ, 2002, p. 105-106). 


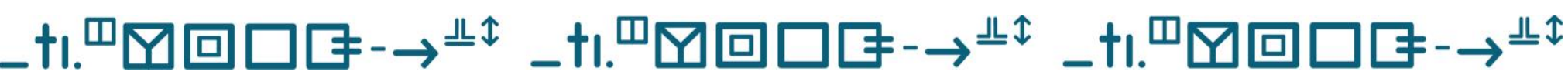

"Luta por reconhecimento": análise crítica dos discursos do Povo Surdo sobre a temática do ENEM 2017

Cleide Emília Faye Pedrosa • Juliana Barbosa Alves

identidade quando forem reconhecidos intersubjetivamente. A seguir, exporemos uma representação da Teoria.

Quadro 1 - Estrutura das relações sociais de reconhecimento

\begin{tabular}{|c|c|c|c|}
\hline $\begin{array}{c}\text { Formas de } \\
\text { Reconhecimento }\end{array}$ & $\begin{array}{c}\text { Relações primárias } \\
\text { (amor, amizade) }\end{array}$ & $\begin{array}{c}\text { Relações jurídicas } \\
\text { (direitos) }\end{array}$ & $\begin{array}{c}\text { Comunidade de } \\
\text { valores } \\
\text { (solidariedade) }\end{array}$ \\
\hline $\begin{array}{c}\text { Modos de } \\
\text { Reconhecimento }\end{array}$ & Dedicação emotiva & Respeito cognitivo & Estima social \\
\hline Autorrelação prática & Autoconfiança & Autorrespeito & Autoestima \\
\hline $\begin{array}{l}\text { Formas de } \\
\text { desrespeito }\end{array}$ & $\begin{array}{l}\text { Maus-tratos e } \\
\text { violação }\end{array}$ & $\begin{array}{l}\text { Privação de direitos e } \\
\text { exclusão }\end{array}$ & Degradação e ofensa \\
\hline $\begin{array}{c}\text { Componentes amea- } \\
\text { çados da personalida- } \\
\text { de }\end{array}$ & Integridade física & Integridade social & “Honra”, dignidade \\
\hline
\end{tabular}

Fonte: Honneth (2009, p. 211, adaptação das autoras).

Descrição da imagem: Quadro intitulado "Estrutura das relações sociais de reconhecimento". O quadro é uma adaptação das autoras da estrutura das relações sociais de reconhecimento de Honneth proposta em 2009. Na primeira coluna, apresentam-se as formas de reconhecimento: as relações primárias; as relações jurídicas e a comunidade de valores. Na segunda coluna, estão os modos de reconhecimento para cada forma de reconhecimento: a dedicação emotiva; o respeito cognitivo e a estima social. Na terceira coluna, listam-se as autorrelações práticas para cada forma de reconhecimento: a autoconfiança; o autorrespeito e a autoestima. Na quarta coluna, constam as formas de desrespeito para cada forma de reconhecimento, maustratos e violação; privação de direitos e exclusão; e degradação e ofensa. Na quinta e última coluna, estão os componentes ameaçados da personalidade de cada forma de reconhecimento: a integridade física; a integridade social e a honra e dignidade.

Foi a partir dos estudos do modelo teórico de Hegel, que Honneth (2009) defende a tese de que, em suas relações intersubjetivas, os sujeitos 


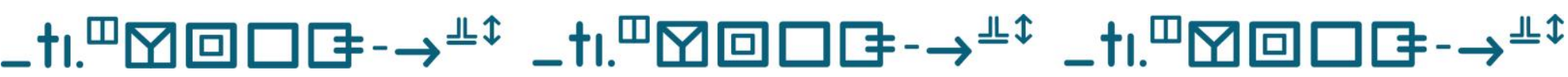

“Luta por reconhecimento": análise crítica dos discursos do Povo Surdo sobre a temática do ENEM 2017

Cleide Emília Faye Pedrosa • Juliana Barbosa Alves

travam uma luta constante por reconhecimento (solidariedade). O autor indica três formas de reconhecimento: o amor, o direito e a solidariedade. Quando o sujeito é desrespeitado, inicia-se, ou pressupomos que deveria começar, sua luta por sua subjetividade (reconhecimento). No amor, base das relações primárias, o sujeito reivindica o reconhecimento como forma de enfrentar os maus-tratos e a violência. Já no direito, base das relações jurídicas, o sujeito busca o respeito cognitivo com o objetivo de enfrentar a exclusão. Na solidariedade, base da comunidade de valores, o sujeito busca a estima social para combater a degradação e a ofensa.

Na sociedade pós-moderna, são os atributos individuais que irão conferir reconhecimento ao sujeito, pois, quando este tem sua particularidade reconhecida, quando se sente importante para a sociedade, se ressignifica (SOUZA, 2016). Quando há uma resposta social para sua luta por reconhecimento, o sujeito passa de sua privação de direitos e exclusão para os modos de reconhecimento através da estima social advinda das comunidades de valores e do respeito cognitivo, e isso por meio de Leis e Decretos que o reconheceram (relações jurídicas).

\section{A Gramática Sistêmico-Funcional}

A proposta da ACD é seguir critérios e categorias textuais para fazer uma análise discursiva e social. Para isso, entra em pauta a contribuição da gramática sistêmico-funcional, enfatizando os usos da língua no contexto social (FUZER; CABRAL, 2014). Trata-se de uma teoria sociossemiótica que prioriza a íntima relação léxico-gramática em interface com a semântica e o discurso (FUZER; CABRAL, 2014).

Entre os sistemas que fazem parte da gramática sistêmico-funcional, utilizaremos o Sistema de Avaliatividade, que categorizará os recursos 


\section{_t..}

“Luta por reconhecimento": análise crítica dos discursos do Povo Surdo sobre a temática do ENEM 2017

Cleide Emília Faye Pedrosa • Juliana Barbosa Alves

léxico-gramaticais empregados nas avaliações (VIAN JR., 2010a). Este Sistema é apresentado da seguinte forma (VIAN JR., 2010a): a) Atitude engloba o Afeto (o sujeito avalia com emoção, expressando sentimentos), o Julgamento (o sujeito julga o caráter, a atitude das pessoas) e a Apreciação (o sujeito atribui valores às coisas, de forma positiva ou negativa); b) Gradação envolve Força (avaliação com mais ou menos força) e Foco (avaliação com mais ou menos foco); e c) Engajamento deixa ver a Monoglossia (voz que não permite questionamento nem diálogo, voz única) e a Heteroglossia (indica referência a outras vozes ou pontos de vista na avaliação).

\section{Fundamentos metodológicos}

Diante de uma pesquisa de cunho social, tendo como aporte teórico a ACD e algumas teorias das ciências sociais, esta pesquisa é classificada como qualitativa-interpretativista (MAGALHÃES; MARTINS; RESENDE, 2017). O objetivo da pesquisa qualitativa é expressar o sentido dos fenômenos do mundo social, como exposto por Magalhães et al. (2017, p. 30): "o tecido social da vida diária, o significado das experiências e o imaginário dos participantes da pesquisa". Já o caráter interpretativista tem como ponto central o significado das ações sociais dos sujeitos.

Em consonância com Marconi e Lakatos (2008), é através da investigação que o pesquisador entra em contato com a realidade do objeto. Para a coleta de dados e constituição do corpus, utilizamos a ferramenta de busca do Facebook. Definimos o mês e o ano correspondentes à data da prova, novembro de 2017. As palavras-chave foram: "redação Enem 2017", "Enem redação surdos" e "Enem surdos". A identificação dos sujeitos discursivos se deu por meio da leitura do 


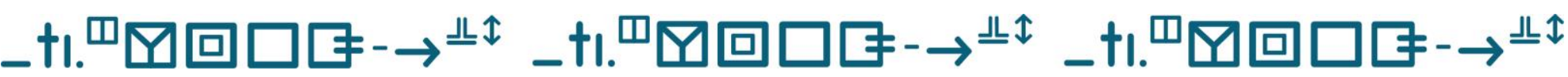

“Luta por reconhecimento": análise crítica dos discursos do Povo Surdo sobre a temática do ENEM 2017

Cleide Emília Faye Pedrosa • Juliana Barbosa Alves

comentário, visto que não havia como identificar um surdo, por exemplo, apenas nas suas informações do perfil. No geral, a identificação veio marcada na sequência discursiva e também na identificação do "Português surdo", ou seja, a escrita do português como segunda língua (L2) para os surdos, que, muitas vezes, deixam marcas características como, por exemplo, a falta de preposição, de conjugação verbal etc., marcas que diferenciam as duas gramáticas (da Língua Portuguesa e da Libras). Assim explica Quadros: "a criança surda deverá adquirir uma L2 que se apresenta numa modalidade lingüística diferente da sua L1, isto é, ela deverá aprender uma língua GRÁFICO-VISUAL enquanto a sua L1 é VISUALESPACIAL" (QUADROS, 1997, p. 111), por isso, verificamos que, "na produção escrita do surdo, há uma forma peculiar de produzir sentido e expressar suas ideias, visto que indivíduos bilíngues, ao vivenciarem uma situação de interação na segunda língua, nunca desativam totalmente a primeira língua" (CORREIA; BARBOSA; OLIVEIRA, 2018, p. 174).

Como caminho, adotamos os passos metodológicos propostos por Pedrosa (2018, p. 159) para a ASCD:

Definir o objeto de estudo; Traçar objetivos de análise; Identificar as áreas de interfaces que atendem aos objetivos; Selecionar as categorias de cada área interfática que alcancem os objetivos propostos; Articular a discursividade à sua materialidade textual; Estabelecer o diálogo entre as categorias de cada área definida e sua materialidade como pressuposto para os resultados analíticos a serem demonstrados; Identificar os sentidos sociais representados e construídos no discurso; Relacionar os sentidos identificados às questões sociais situadas/contextualizadas.

Desta forma, seguindo os dois primeiros passos, objeto e objetivo da análise, norteamos os passos seguintes. Nos terceiro e quarto passos, com 


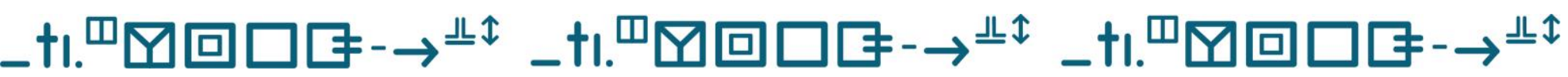

“Luta por reconhecimento": análise crítica dos discursos do Povo Surdo sobre a temática do ENEM 2017

Cleide Emília Faye Pedrosa • Juliana Barbosa Alves

base nos objetivos, selecionamos as áreas que embasaram os estudos, a saber, Análise Crítica do Discurso, Estudos Surdos e Luta por Reconhecimento e escolhemos as categorias para cada área selecionada. Nos passos cinco e seis, diante da articulação entre a discursividade e a materialidade, ocorre um diálogo entre as categorias de análise e sua materialidade. Por fim, nos passos sete e oito, as discussões e reflexões das análises são apresentadas imbricadas a questões sociais contextualizadas.

\section{Discursos do Povo Surdo sobre a temática do ENEM 2017 e sua luta por reconhecimento}

Viver num regime democrático garante, ou deveria garantir, aos atores sociais se organizarem em torno de causas comuns, terem livre ação e direito a manifestações na sociedade, sejam manifestações presenciais ou virtuais, como ocorre através de discursos opinativos. Essa configuração política se conforma na base de três princípios: "o 'reconhecimento dos direitos fundamentais', a 'representatividade social dos dirigentes e da sua política' e a 'consciência de cidadania', ou seja, de que a pessoa pertence a uma coletividade fundada sobre o direito" (MAGALHÃES; MARTINS; RESENDE, 2017, p. 172, grifo dos autores).

Considerando o direito a partir de discursos opinativos, as análises tomarão como corpus os posicionamentos dos Surdos sobre a temática do ENEM 2017. Contextualizaremos com a aplicação das teorias destacadas, como a ACD, a ASCD, a Gramática Sistêmico-Funcional e a Luta por Reconhecimento.

Exemplo 0110: "Este vídeo foi feito com minha indignação, após eu ver um post da minha ex professora reclamando do tema da prova do Enem 2017. E servirá também 


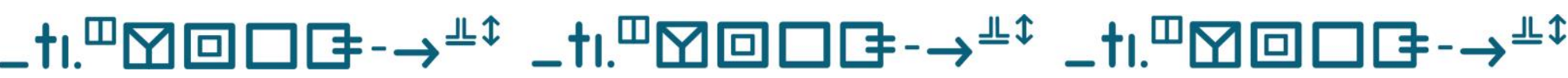

“Luta por reconhecimento": análise crítica dos discursos do Povo Surdo sobre a temática do ENEM 2017

Cleide Emília Faye Pedrosa • Juliana Barbosa Alves

para todos que fizeram a prova e, por motivo algum estão postando em suas redes sociais uma chuva de opiniões imaturas acerca do tema...MAIS RESPEITO. MENOS IGNORÂNCIA. MAIS ALTERIDADE. Afinal, Vocês não conhecem as cicatrizes dos surdos, Vocês não conhecem aonde seus sapatos apertam, Vocês não conhecem os caminhos por eles percorridos, FALEM MENOS!"

No primeiro passo da análise, observamos que o sujeito discursivo do post travou uma luta por reconhecimento, pois ela se sente desrespeitada na solidariedade, reagindo ao ver em um post em que sua ex-professora não respeitou sua particularidade, enquanto ex-professora de surda, demonstrando, com isso, desinteresse afetivo (HONNETH, 2009). Desse modo, assumindo-se como membro de uma comunidade cultural, vem expressar seu discurso para ser reconhecido enquanto surda. Ela estende sua indignação quanto ao desrespeito à causa surda no trecho "opiniões imaturas", em que observamos que ela faz o julgamento do comportamento de pessoas que fizeram comentários negativos acerca do tema (ALMEIDA, 2010), numa heteroglossia com vozes divergentes, até mesmo a de uma professora que trabalhou com surdos (VIAN JR., 2010b).

O uso da caixa alta no trecho "MAIS RESPEITO, MENOS IGNORÂNCIA, MAIS ALTERIDADE" contribui para chamar atenção para seu comentário, usando uma gradação para acentuar seu discurso (SOUZA, 2010), utilizando-o para divulgação dos problemas sociais enfrentados pelos sujeitos surdos, pois, como nos aponta Resende (2017), tendo como referência Fairclough (2008), a linguagem tem uma relação especial com outros elementos sociais, uma vez que os textos que formulamos funcionam como parte essencial das maneiras como nos comportamos na sociedade. Identificamos, assim, um discurso carregado de afeto (ALMEIDA, 2010) por toda a carga histórica dos surdos, dos seus sofrimentos e das suas lutas, que são menosprezados por pessoas que desconhecem tais 


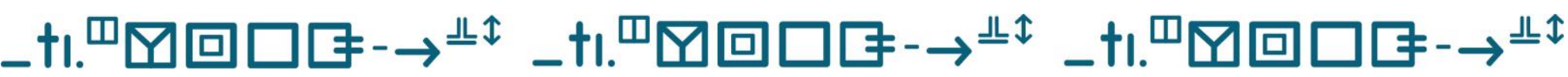

“Luta por reconhecimento": análise crítica dos discursos do Povo Surdo sobre a temática do ENEM 2017

Cleide Emília Faye Pedrosa • Juliana Barbosa Alves

fatos ("Vocês não conhecem as cicatrizes dos surdos, (...) Vocês não conhecem os caminhos por eles percorridos").

Anular o passado e requerer o presente se mostrou como artefato cultural para os surdos. Um passado imerso na obrigação de serem ouvintes e, em função disto, aceitar que os outros fizessem a sua história, os dominassem, se tornou a marca mais deprimente. Diante disto, surgem novos feitos e novas interpretações no cotidiano. Neste sentido, se prosseguirmos com as velhas realidades, narradas como que no tempo colonial, perigamos escrever uma história de holocausto, de dominação, de lamentos. Mas não é por aí... Temos outros caminhos que, mesmo desconhecidos, merecem ser trazidos à tona, vivenciados e narrados por constituírem a genuína história natural e cultural dos surdos (PERLIN; STROBEL, 2014, p. 20).

O surdo tem sido visto por uma perspectiva patológica como portador de uma deficiência, enfrentando um discurso de normalização para fazer parte da maioria "normal" da sociedade (GESSER, 2009). A valorização da cultura e da identidade surdas é essencial para a construção de uma nova visão sobre a surdez. Essa é a sua luta por reconhecimento!

Exemplo 02: "NOSSA estou CHOCADA! Deu vontade de chorar lendo esses comentários ridículos, muito triste de ver..."Tanto ódio do tema da redação enem que se eu ver um surdo na rua eu meto-le uma pesada" mas o que??? O que nós fizemos? O MEC apenas queria o reconhecimento dos surdos, temos que valorizar a Libras porque é a sua segunda língua oficial... Nossa eu estou sem palavras, muito triste mesmo! Essas pessoas, sem noção.

Comentário compartilhado: Acabei de sair da sala do Enem, que tema de redação bosta, MISERICÓRDIA."

Nessa sequência discursiva, percebemos no início a escolha do uso de caixa alta, utilizando uma gradação para intensificar seu discurso, em uma escala com valores variando "entre um pólo constituído de termos que 


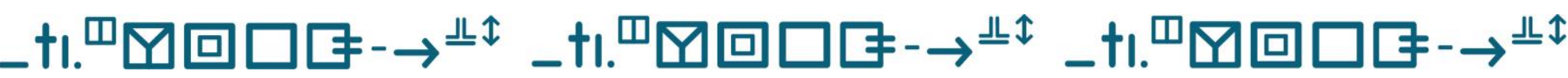

“Luta por reconhecimento": análise crítica dos discursos do Povo Surdo sobre a temática do ENEM 2017

Cleide Emília Faye Pedrosa • Juliana Barbosa Alves

expressam avaliações socialmente consideradas como menos intensas e um outro pólo constituído de itens que indicam avaliações consideradas mais intensas" (SOUZA, 2010, p. 191), o que combina com a escolha lexical em que assentou sua opinião, verificada no trecho "CHOCADA". Realmente, é chocante como, em pleno século XXI, os surdos são vítimas do ódio de pessoas escolarizadas, pois quem foi fazer a prova do ENEM são pessoas que, no mínimo, concluíram, ou estão concluindo, o Ensino Médio. Esse é um retrocesso às sociedades antigas, como Grécia e Roma, por exemplo, em que os Surdos eram torturados e mortos, considerados imperfeitos e, por isso, indignos de fazer parte da sociedade (CARVALHO, 2007).

Nos trechos "deu vontade de chorar" e "muito triste", percebemos um discurso na categoria Afeto da Gramática Sistêmico-Funcional (GSF), considerando que esse é um recurso semântico para representar, linguisticamente, as emoções no discurso. A avaliação do escritor diz respeito a como se sente emocionalmente em relação aos acontecimentos, às pessoas e às coisas (ALMEIDA, 2010).

Na sequência "tanto ódio" e "essas pessoas sem noção", o sujeito discursivo faz um Julgamento de estima social, no qual põe em questão o comportamento negativo das pessoas que falaram mal do tema da redação do Enem. Segundo Almeida (2010), esse tipo de julgamento está baseado em regras de comportamento formadas por uma cultura particular, e, dessa forma, o julgamento pode ser positivo ou negativo. Então o que se verifica é que, até mesmo na atualidade, o preconceito contra os Surdos permanece, não sendo fácil para o povo conviver com tal desfeita da sociedade em que estão inseridos. Faltam-lhes a solidariedade e o cumprimento das Leis e dos Decretos que Ihes beneficiam, resultando em formas de desrespeito, de acordo com a teoria da "Luta por 


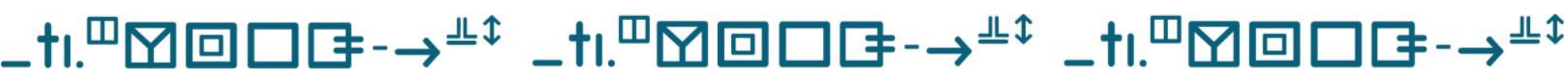

“Luta por reconhecimento": análise crítica dos discursos do Povo Surdo sobre a temática do ENEM 2017

Cleide Emília Faye Pedrosa • Juliana Barbosa Alves

Reconhecimento" (HONNETH, 2009): maus-tratos e violação (relações primárias); privação de direitos e exclusão (relações jurídicas); degradação e ofensa (comunidade de valores).

O sujeito discursivo demonstra que é engajada com a cultura e a identidade surdas, ela se identifica como surda e fala em nome de toda sua comunidade no trecho "O que nós fizemos". As mudanças sociais e culturais vivenciadas pelos surdos, após o discurso, naturalizado, de normalização, levou o surdo a se enxergar como sujeito e assumir sua identidade, mudando, com isso, suas práticas discursivas.

A ASCD (PEDROSA, 2012) recontextualiza a proposta do sociólogo Bajoit (2008) para as análises do discurso sobre mudanças sociais e culturais. Para o estudioso, quando uma comunidade, como a surda, por exemplo, passa por mudanças na maneira como estabelece relações sociais, ela vivencia, ao mesmo tempo, a velha e a nova maneiras: a primeira, tentando sobreviver, e a segunda, se impondo, resistindo. São, pois, aspectos confirmados na postagem do Exemplo 2, quando os surdos pensam que já venceram o preconceito social ao verificarem que o MEC escolheu uma temática que os beneficia (a nova maneira) e que chama atenção para sua causa, ao passo que são identificadas, nas redes sociais, postagens que incitam o ódio, que causam exclusão (a velha maneira resistindo). Como explica Bajoit (2008, p. 48), "portanto, analisar a mudança significa, em primeiro lugar, descobrir a maneira antiga, em seguida, explicar porque e como ele está transformando e, finalmente, identificar as práticas que poderiam ser uma nova forma" de mudança social. Desse modo, o sociólogo afirma que essas mudanças socioculturais se definem pela coexistência dos modelos antigo e novo, levando os atores sociais a refletirem sobre suas práticas e vivenciarem períodos intermediários, 


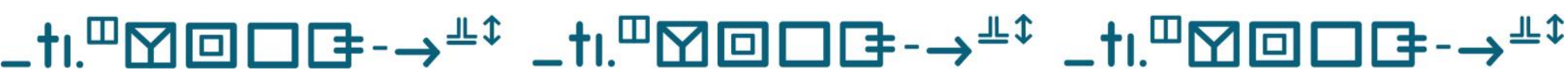

“Luta por reconhecimento": análise crítica dos discursos do Povo Surdo sobre a temática do ENEM 2017

Cleide Emília Faye Pedrosa • Juliana Barbosa Alves

períodos esses que os Surdos almejam que passem, de forma que possam viver o resultado de sua luta por reconhecimento.

Em sequência, ainda podemos indicar a categoria funcional da Apreciação que diz respeito às avaliações sobre coisas, objetos e fenômenos, além de bens e serviços ao nosso redor (ALMEIDA, 2010). Identifica-se essa categoria no trecho em que o sujeito faz uma apreciação positiva quanto ao MEC: "O MEC apenas queria o reconhecimento dos surdos". É possível dizer, também, que houve, nessa sequência, um sentimento de autorrespeito, pois se experienciou o respeito do seu direito enquanto parte de uma comunidade, visto que o reconhecimento jurídico oferece ao sujeito a condição de se colocar positivamente perante ele mesmo (HONNETH, 2009).

Exemplo 03: "Sobre o ENEM 2017. Sobre o tema da redação do Enem 2017. Dom Pedro Il que de onde estiver deve ter visto o trabalho dele não foi em vão. Escolarizou as classes marginalizadas no Brasil Surdos, negros, Deficiente intelectual, escravos e cegos e hoje a comunidade surda teve a oportunidade de presenciar que a parcela da população brasileira tiveram de refletir sobre o tema do Enem. VITÓRIA PARA A EDUCAÇÃO DE SURDOS QUE ATÉ QUE ENFIM É VALORIZADA SAINDO DO CASULO DA CLASSE MINORIZANTE...... Graças a Deus".

No início da sequência, o sujeito discursivo utiliza um recurso heteroglóssico do subsistema Engajamento (GSF) ao trazer uma voz para endossar seu comentário (VIAN JR., 2010b) uma vez que compartilha solidariedade com ela no trecho "Dom Pedro II que de onde estiver deve ter visto o trabalho dele não foi em vão". Historicamente, isso nos remete à fundação do INES, referência, até hoje, na educação de surdos, independentemente de alguns altos e baixos, como, por exemplo, quando 


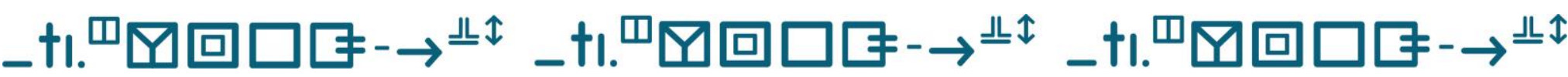

“Luta por reconhecimento": análise crítica dos discursos do Povo Surdo sobre a temática do ENEM 2017

Cleide Emília Faye Pedrosa • Juliana Barbosa Alves

retrocedeu no uso de línguas de sinais por influência do resultado da imposição do oralismo, no Congresso de Milão.

Por todo o engajamento na luta da causa surda, percebemos emoção no discurso, através do recurso semântico do Afeto (ALMEIDA, 2010), identificado em "a comunidade surda teve a oportunidade de presenciar", expressando autoestima ao ver a comunidade surda tendo espaço e sendo reconhecida, com suas necessidades ao ser tema de redação numa prova de amplo alcance como o Enem. Mais de 7,6 milhões de candidatos tiveram de, a gosto ou contragosto, desenvolver um texto sobre a temática ("a população brasileira tiveram de refletir"). Nos estudos críticos do discurso, a posição de engajamento nos leva a construir ações que visam o empoderamento e a conscientização daqueles que se encontram em situações de opressão (MELO, 2018).

Para finalizar, destacamos que o sujeito discursivo reconhece que os surdos fazem parte de uma classe vulnerável e que, portanto, sua educação está em um "casulo", e, devido ao tema da redação do Enem, esse assunto ganhou visibilidade. Dessa forma, o sujeito discursivo faz uma apreciação da prova do Enem, avaliando-a de maneira positiva, como observamos no trecho: "A EDUCAÇÃO DE SURDOS QUE ATÉ QUE ENFIM É VALORIZADA". Esse é, portanto, mais um passo da comunidade surda na luta por reconhecimento.

Exemplo 04: "O tema da redação realmente me comoveu. Me comoveu porque finalmente vi que eu existia. Existia ali o surdo. Eu sempre me senti excluído por ter minha deficiência. Mas pegar uma redação com este tema realmente foi uma grande oportunidade. Oportunidade de levantar a voz do silêncio e mostrar que a surdez pode nos levar para além das fronteiras". 


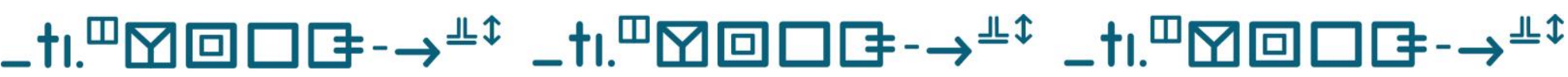

“Luta por reconhecimento": análise crítica dos discursos do Povo Surdo sobre a temática do ENEM 2017

Cleide Emília Faye Pedrosa • Juliana Barbosa Alves

O parágrafo é iniciado com o sujeito discursivo fazendo uso do recurso Afeto, expressando seus sentimentos (ALMEIDA, 2010), o que é observado no trecho repetido "me comoveu". Como vemos, na maioria dos comentários dos sujeitos surdos, a carga histórica de opressão desse grupo minoritário é resgatada em seus discursos, justificando assim nossa ancoragem teórica na ACD, pois, como defende Gonçalves-Segundo (2018), o objetivo principal dessa prática é a denúncia de relações de poder e de opressão, a fim de possibilitar uma sociedade mais justa e democrática, na qual todos tenham direitos iguais.

Observamos ainda, na escolha lexical "oportunidade", a satisfação por acreditar que a causa em que ele está engajado será projetada "para além das fronteiras". O sujeito se reconhece como membro de uma comunidade ("vi que eu existia"; "Existia ali o surdo"), e ser membro de uma comunidade significa compartilhar experiências, compartilhar a mesma cultura, "isto origina a identificação de pertencer a um povo distinto, caracterizado por compartilhar língua de sinais, valores culturais, hábitos e modos de socialização" (PERLIN; STROBEL, 2014, p. 25).

Percebemos que esse sujeito discursivo, por ter sua particularidade reconhecida (HONNETH, 2009) e por se sentir importante para a sociedade, tem a oportunidade de se ressignificar, de ressignificar sua luta e obter alguma vitória, como essa de sua singularidade ser tema de uma prova nacional. Em "A surdez pode nos levar para além das fronteiras", indica passos de mudanças sociais e culturais da sociedade que excluía os surdos ("Eu sempre me senti excluído"). Como as ordens sociais produzem suas próprias vítimas (ORTÚZAR, 2016), também deve ser responsável por desenvolver estratégias e dispor recursos para enfrentar suas injustiças. 


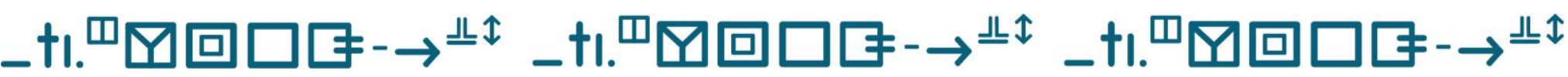

“Luta por reconhecimento": análise crítica dos discursos do Povo Surdo sobre a temática do ENEM 2017

Cleide Emília Faye Pedrosa • Juliana Barbosa Alves

\section{Considerações (quase) finais}

A Análise Crítica do Discurso estabelece diálogos teóricos em prol dos grupos vulneráveis. Ao articular teorias e métodos, ela traz resultados favoráveis à luta política desses grupos. E, ao trabalhar com a $A C D$, nos engajamos nessa luta política em prol dos grupos que sofrem em relações desiguais de poder.

É histórico que o Povo Surdo foi excluído, que tiveram seus direitos denegados, sua cultura, seus valores, sua língua foram menosprezados. Toda essa opressão levou muitos sujeitos surdos a assumirem uma identidade subalterna diante da cultura ouvinte. Acreditamos que, no entanto, os sujeitos surdos, que se manifestaram nos discursos analisados, demonstraram que o Povo Surdo está mais conscientizado e ciente de seus direitos e engajado na luta por reconhecimento em suas diversas formas. Observamos o empoderamento e protagonismo desses sujeitos quanto à sua cultura e à sua língua.

Por meio do recurso da gradação (GSF), no qual é possível demostrar o comprometimento do produtor textual em suas avaliações, percebemos a intensificação nos discursos de reinvindicação (MAIS RESPEITO. MENOS IGNORÂNCIA. MAIS ALTERIDADE - Exemplo 1) e de denúncia (CHOCADA! Exemplo 2; SAINDO DO CASULO DA CLASSE MINORIZANTE - Exemplo 3), mostrando uma tomada de consciência do Povo Surdo frente aos seus direitos, numa demonstração de protagonismo nestes espaços discursivos.

Essa é, portanto, uma luta por reconhecimento que ultrapassa sua identificação através de uma análise linguística baseada na Gramática Sistêmico-Funcional, indo além, pelo caminho de uma gramática moral dos conflitos sociais. Em síntese, a luta social de um grupo vulnerável deve nos causar sentimentos morais de injustiça, porque a luta social acontece 


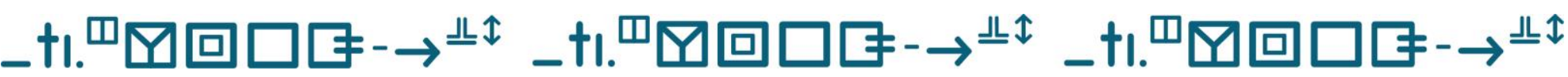

“Luta por reconhecimento": análise crítica dos discursos do Povo Surdo sobre a temática do ENEM 2017

Cleide Emília Faye Pedrosa • Juliana Barbosa Alves

PEDROSA, C. E. F. Análise crítica do discurso: do linguístico ao social no gênero midiático (interface: letras e comunicação social). São Cristóvão: Editora UFS; Aracaju: Fundação Oviêdo Teixeira, 2008.

PEDROSA, C. E. F. Abordagem Sociológica e Comunicacional Do Discurso (ASCD): uma corrente para fazer Análise Crítica do Discurso. PARTE 1: Herança teórica da Sociologia (Aplicada) para a Mudança Social. Natal: UFRN, 2012. Texto fundador. Disponível em: http://ascd.com.br/v1/. Acesso em: 29 jan. 2022.

PEDROSA, C. E. F. Análise Crítica do Discurso no PPGL: pesquisas e contribuições sociais. In: RAMALHO, C. B.; LIMA, G. de O. S. (Orgs.). Estudos Linguísticos e Literários: Edição comemorativa 10 anos do Programa de Pós-Graduação em Letras da UFS. Aracaju: Criação, 2018. p. 153-178.

PERLIN, G.; STROBEL, K. História cultural dos surdos: desafio contemporâneo. Educar em Revista, Edição Especial, n. 2, p. 17-31, 2017. Curitiba: Editora UFPR, 2014.

QUADROS, R. M. Educação de surdos: aquisição da linguagem. Porto Alegre: Artmed, 1997.

RAMALHO, V.; RESENDE, V. de M. Análise de discurso (para a) crítica: o texto como material de pesquisa. Campinas, SP: Pontes Editores, 2011.

RESENDE, V. de M. Análise de discurso crítica e realismo crítico: implicações interdisciplinares. Campinas, SP: Pontes Editores, 2009.

RESENDE, V. de M. Análise de discurso crítica: reflexões teóricas e epistemológicas quase excessivas de uma analista obstinada. In: RESENDE, V. de M.; REGIS, J. F. da S. (Orgs.). Outras perspectivas em análise de discurso crítica. Campinas, SP: Pontes Editores, 2017. p. 11-51.

RESENDE, V. de M. (Org.). Decolonizar os estudos críticos do discurso. Campinas, SP: Pontes Editores, 2019.

RESENDE, V.; RAMALHO, V. Análise de Discurso Crítica. São Paulo: Editora Contexto, 2006. 


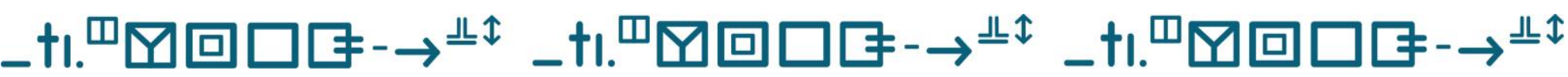

“Luta por reconhecimento": análise crítica dos discursos do Povo Surdo sobre a temática do ENEM 2017

Cleide Emília Faye Pedrosa • Juliana Barbosa Alves

RESENDE, V. de M.; REGIS, J. F. da S. (Orgs.). Outras perspectivas em análise de discurso crítica. Campinas, SP: Pontes Editores, 2017.

ROCHELLE, E. L. Le Congrés de Milan pour l'amélioration du sort des sourds- muets. Paris: M. Saint-Jorre, 1880.

SÁ, N. R. L. de. Cultura, poder e educação de surdos. Manaus: Editora da Universidade Federal do Amazonas, 2002.

SOUZA, A. A. de. Gradação: força e foco. In: VIAN JR., O.; SOUZA, A. A. de; ALMEIDA, F. A. S. D. P. (Orgs.). A linguagem da avaliação em língua portuguesa. Estudos sistêmico-funcionais com base no Sistema de Avaliatividade. São Carlos: Pedro \& João Editores, 2010. p. 191-203.

SOUZA, M. C. de. A "Luta por reconhecimento" no facebook: a comunicação social nas redes sociais, uma interpretação sociológica. $103 f$. Dissertação (Mestrado em Sociologia) - Universidade Federal de Sergipe, São Cristóvão, 2016.

SOUZA, V. dos R. M. Tobias Leite: educação dos surdos no século XIX. São Cristóvão: Editora UFS, 2014.

VAN DIJK, T. A. Critics: discourse analysis in Latin America. Discourse \& Society, London, v. 8, n. 2, p. 163-164, 1997.

VIAN JR., O. O Sistema de Avaliatividade e a linguagem da avaliação. In: VIAN JR., O.; SOUZA, A. A. de; ALMEIDA, F. A. S. D. P. (Orgs.). A linguagem da avaliação em língua portuguesa. Estudos sistêmico-funcionais com base no Sistema de Avaliatividade. São Carlos: Pedro \& João Editores, 2010a. p. 19-29.

VIAN JR., O. Engajamento: monoglossia e heteroglossia. In: VIAN JR., O.; SOUZA, A. A. de; ALMEIDA, F. A. S. D. P. (Orgs.). A linguagem da avaliação em língua portuguesa. Estudos sistêmico-funcionais com base no Sistema de Avaliatividade. São Carlos: Pedro \& João Editores, 2010b, p. 33-40.

VIEIRA, J. A.; MACEDO, D. S. Conceitos-chave em análise de discurso crítica. In: BATISTA JR., J. R. L.; SATO, D. T. B.; MELO, I. F. de. (Orgs.). Análise de discurso crítica para linguistas e não linguistas. São Paulo: Parábola, 2018. p. 48-77. 


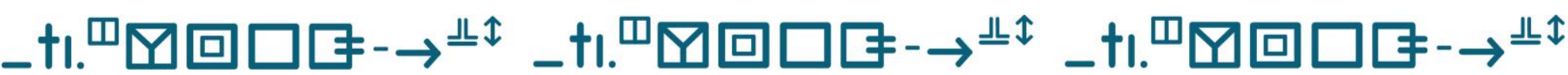

"Luta por reconhecimento": análise crítica dos discursos do Povo Surdo sobre a temática do ENEM 2017

Cleide Emília Faye Pedrosa • Juliana Barbosa Alves

WODAK, R. De que trata el análisis crítico del discurso (ACD). Resumen de su historia, sus conceptos fundamentales y sus desarrollos. In: WODAK, R.; MEYER, M. (Orgs.). Métodos de análisis crítico del discurso. Barcelona, Espanha: Gedisa, 2003. p. 17-34.

WODAK, R.; MEYER, M. Métodos de análisis crítico del discurso. 2. ed. Barcelona, Espanha: Gedisa, 2009.

\section{Publisher}

UNIVERSIDADE FEDERAL DE GOIÁS. CURSOS DE LETRAS: LIBRAS E DE LETRAS: TRADUÇÃO E INTERPRETAÇÃO EM LIBRAS/PORTUGUÊS DA FACUldade de LeTRAS/UfG. Publicação No PORTAL de PERIÓdicos UFG. AS IDEIAS EXPRESSADAS NESTE ARTIGO SÃO DE RESPONSABILIDADE DE SUAS AUTORAS, NÃO REPRESENTANDO, NECESSARIAMENTE, A OPINIÃO DOS EDITORES OU DA UNIVERSIDADE.

\section{Notas}

\footnotetext{
${ }^{1}$ A contextualização deste artigo, focado na comunidade surda, advém do projeto, desenvolvido com bolsa de iniciação científica do CNPq, "Papel da análise crítica do discurso nas práticas sociais: desigualdade social, aprendizagem cidadã e empoderamento" (PDV 64012018), que envolve outras frentes de pesquisa que trabalham com grupos vulneráveis, como por exemplo: idosos, crianças, mulheres.

2 Disponível em: https://www.mdh.gov.br/todas-as-noticias/2019/janeiro/nomeada-asecretaria-nacional-dos-direitos-da-pessoa-com-deficiencia. Acesso em: 14 mai. 2019.

3 Disponível em: https://www.in.gov.br/en/web/dou/-/portarias-de-16-de-setembro-de2021-345458551. Acesso em: 29 jan. 2022.

4 Disponível em: https://www.librasol.com.br/mec-escolhe-uma-surda-para-cargo-dediretora-de-politicas-de-educacao-bilingue-de-surdos/. Acesso em: 14 mai. 2019.

5 Disponível em: https://pesquisa.in.gov.br/imprensa/servlet/INPDFViewer?jornal=529\&pagina=36\&data=20/ 01/2020\&captchafield=firstAccess. Acesso em: 29 jan. 2021.

6 Tradução nossa. Original: "que por la existencia de alguna teoria o metodología común" (WODAK, 2003, p. 22).

${ }^{7}$ Disponível em: www.ascd.com.br. Acesso em: 29 jan. de 2022.
} 


\section{_tı.}

“Luta por reconhecimento": análise crítica dos discursos do Povo Surdo sobre a temática do ENEM 2017

Cleide Emília Faye Pedrosa • Juliana Barbosa Alves

8 Original: "In those European schools where articulation has been accepted as an adjunct, the main reliance being on the language of signs, the manual alphabet and writing". Agradecemos a Iris da Silva Santos pela tradução de todo o artigo.

9 Tradução nossa. Original: “[...] mais, en dépit de quelques résistances, la méthode de l'articulation l'emporte visiblement. Son triomphe s'affirme dans une résolution ainsi formulée: Le Congrés, Considérant l'incontestable supérioritéde la parole sur les signes pour rendre le Sourd-Muet à la société et lui donner une plus parfaite connaissance de la langue, Déclare que la méthode orale doit être préférée à celle de la mimique pour l'éducation et l'instruction des Sourds-Muets".

10 Todos os exemplos são fiéis aos escritos no Facebook. Especificamente, no exemplo 1, o sujeito discursivo postou um vídeo em Libras seguido da tradução para a língua portuguesa. 